\title{
Marriage, widowhood, and health-care use
}

\author{
Theodore J. Iwashyna ${ }^{\mathrm{a}, *}$, Nicholas A. Christakis ${ }^{\mathrm{a}, \mathrm{b}}$

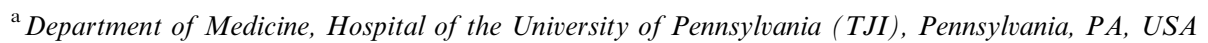 \\ ${ }^{\mathrm{b}}$ Department of Health Care Policy Harvard Medical School, Harvard University, MA, USA
}

\begin{abstract}
Despite suggestive evidence, there has been no adequately powered systematic study of the ways in which marital status influences health care consumption. Using a novel data set of 609,016 newly diagnosed, seriously ill elderly individuals in the USA, and employing hierarchical linear models, we look at differences in the experience of hospitalization as a function of marital status. We find that the married consistently use higher quality hospitals and have shorter lengths of stay. On the other hand, the married and the widowed appear to receive similar quality care once they are in the hospital. Marital status thus has a substantial impact on the health care obtained by the elderly. We suggest that these patterns are most consistent with spouses exerting their benefits by functioning as higher-order decision-makers than as home health assistants.
\end{abstract}

(C) 2003 Elsevier Ltd. All rights reserved.

Keywords: Marriage; Widowhood; Health; Mortality; Health-care use; USA

\section{Introduction}

The marital status composition of the elderly is changing, particularly in the United States. (US Bureau of the Census, 1996) Limited previous research suggests this demographic shift could have substantial implications for health and health care resource utilization, especially since the growing population of widows and widowers appears to be less healthy than the married. (Korenman, Goldman, \& Fu, 1997; Lillard \& Waite, 1995; Mineau, Smith, \& Bean, 2002; Ross, Mirowsky, \& Goldsteen, 1990; Smith \& Waitzman, 1994; Smith \& Zick, 1994) In order to appropriately design interventions that might remedy or prevent the adverse health sequelae of widowhood, and in order to better understand the mechanisms by which spouses facilitate health, an investigation of how marital status is associated with health-care use would be informative.

\footnotetext{
*Corresponding author. Department of Health Care Policy Harvard Medical School, Harvard University, 180 Longwood Ave, Boston, MA 02115, USA. Tel.: + 1-617-432-1909; fax: + 1617-432-5891.

E-mail address: iwashyna@alumni.princeton.edu (T.J. Iwashyna).
}

Some prior work does indeed suggest that there are differences in the types of health care the married receive. The married are more likely to have a primary care physician (Sox, Schwartz, Burstin, \& Brennan, 1998). Married Hispanic elderly are more likely to get influenza and pneumococcal vaccines than the unmarried Hispanic elderly (Mark \& Paramore, 1996). Married women present with earlier stage breast cancer, and may have better cancer screening behavior (Goodwin, Hunt, Key, \& Samet, 1987; Lannin et al., 1998). The recently widowed may have more hospitalizations, and have greater use of mental health services (Prigerson, Maciejewski, \& Rosenheck, 1999). When hospitalized, the married have been found to have shorter lengths of stay for a number of common conditions in two different types of hospital (Chin \& Goldman, 1997; Kuykendall, Ashton, Johnson, \& Geraci, 1995). The married are less likely to use nursing homes (Freedman, 1996; Freedman, Berkman, Rapp, \& Ostfeld, 1994). And, at the end of life, the married experience better pain control at nursing homes (Bernabei et al., 1998). Taken together, these scattered studies suggest that the married may get better care than the unmarried. However, beyond one highly suggestive but somewhat underpowered study (Prigerson et al., 1999) there has 
not been a systematic examination of the impact of marriage on health-care use per se. The present work attempts to fill this gap by looking at the case of first hospitalization for a serious, life-threatening illness.

An additional pragmatic motivation for our work is that past work has generally focused on aspects of the health care system other than hospitals, despite the fact that hospitals are of enormous importance. Hospitalization costs account for $43 \%$ of Medicare spending and $33 \%$ of all US health care dollars (Health Care Financing Administration, 1998; Levit et al., 2000). The hospital remains the central institution in the treatment - and cure where available - of many serious illnesses. Pertinently for present purposes, there are wide variations in the quality of care provided at different hospitals (Kohn, Corrigan, \& Donaldson, 2000) and this quality might in principle vary according to marital status. Moreover, many prior studies of health-care use conflate the need for health care (e.g., onset of a serious illness) with the type of care used (e.g., hospitalization vs. outpatient management). In addition, these studies conflate where people go when they are feeling ill with where patients are referred once they carry a diagnosis. In order to understand the impact of marital status on health-care use, these issues need to be disentangled. We furthermore choose to study the impact of marital status on the experience of the initial hospitalization for serious illness.

We consider two questions here. First, we ask, given the set of hospitals available to a patient, how is marital status related to the attributes of the hospital used at the onset of a serious illness? In particular, we ask: are the married more likely to go to teaching hospitals? To hospitals nominated as "Best Hospitals" by the wellknown US News \& World Report ratings? To hospitals offering higher technology services? Second, to further explore the link between marital status and health-care use, we ask, given the hospital used, how do patients' experiences in that hospital vary with marital status? In particular, we ask: are the married likely to have shorter or longer lengths of stay? Do the married receive the same quality of care therein? By examining in detail the relationship of marital status to hospital use and hospital experience, we can differentiate among possible explanations for the well-known beneficial effect of marriage on health - and offer some tentative suggestions about the sorts of interventions that might help offset of health disadvantage of the widowed.

\section{Methods}

\section{Overview}

We use a data set drawn from the administrative records of the Medicare system. This system provides care to over $96 \%$ of Americans at least age 65 (Hatten, 1980 ). We look at elderly individuals newly diagnosed with 1 of 13 serious illnesses in 1993 chosen primarily because, in toto, they account for a large fraction of deaths in the US. After extensive parametric controls for health at baseline and traditional demographic factors, and after accounting for the choices available to the patients using fixed effect models that account for the hospitals in a patient's vicinity, we look at differences in the type of hospital used and the experience of care at that hospital as a function of marital status. Given our focus on health-care use among the elderly, this means that the dominant comparison must be between the married and the widowed.

\section{Data}

The subjects analyzed here are drawn from the care after the Onset of Serious Illness (COSI) data set, a data set we have built based on Medicare claims (Christakis, Iwashyna, \& Zhang, 2002). COSI contains clinical, demographic, and other information about a population-based cohort of elderly patients identified at the time of initial diagnosis with a serious illness in 1993. In the first stage of data development, a cohort of all patients newly diagnosed with one of 13 diagnoses were identified: cancer of the lung, colon, pancreas, urinary tract, liver or biliary tract, head or neck, or central nervous system, as well as leukemia or lymphoma, stroke, congestive heart failure, hip fracture, or myocardial infarction (MI). Empanelment into the analytic cohort for this project required that the patient (a) be newly diagnosed in 1993; (b) be at least 68 years old; (c) have an ascertainable marital status in the claims, (d) live in the 50 United States or the District of Columbia, and (e) have a successful linkage to certain county and hospital-level data sets. A total of 638,918 individuals had an incident empanelling diagnosis, met our age and geographic restrictions, and were matched to an identified spouse, that is, met criteria (a) through (d) above.

Briefly, the development of the COSI cohort relies initially on 1993 inpatient hospitalization records. These records, contained in the so-called MedPAR file, represent a complete enumeration of hospitalizations for Medicare beneficiaries occurring during 1993. For individuals who had a hospitalization with one of the above 13 conditions in 1993, we used well-described methods to ascertain whether their condition could be considered incident or prevalent. In general, we relied upon the ICD-9-CM definitions used by the SEER program for cancers, and on the definition with the highest published sensitivity and specificity for noncancer conditions. (Significant additional detail, including the precise ICD-9-CM codes used, sources for alternative definitions not used, and some external validations are available elsewhere (Christakis et al., 
2002.) We included in COSI only those malignancies that were deemed incident at the time of their first hospitalization for one of the conditions after reviewing three prior years of claims (McBean, Babish, \& Warren, 1993, 1994). In the case of heart attack, hip fracture, and stroke, we used similarly validated approaches to include only new events for a patient. (Benesch et al., 1997; Krumholz et al., 1998; Lauderdale, Furner, Miles, \& Golderberg, 1993) All other diseases that patients may have had (for example, as noted on prior hospitalizations for other conditions) were also collected and were treated as co-morbidities according to a previously published method (Charlson, Pompei, Ales, \& MacKenzie, 1987; Deyo, Cherkin, \& Ciol, 1992; Zhang, Iwashyna, \& Christakis, 1999).

Using previously described methods, we uniquely identified the spouse (alive or dead) of members through the HCFA data (Iwashyna, Brennan, Zhang, \& Christakis, 2002; Iwashyna, Zhang, Lauderdale, \& Christakis, 1998; Iwashyna et al., 2000). This approach takes advantage of information included in the so-called health insurance claim number (HIC) that is assigned to every Medicare beneficiary based, in part, on how they qualify for Medicare benefits; in particular, many individuals have a beneficiary claim number group (BIC) indicating that they are the spouse or widow of another Medicare beneficiary. In order to be detected, a spouse must have survived to qualify for Medicare at any point since the program's inception; no actual utilization was necessary. (This excludes from our sample those who are married to much younger spouses, or whose spouse died before the age of 65.) This method allows us to identify married and widowed individuals; it does not allow the reliable distinction between the never married and the divorced. In order to exclude divorced and separated couples, we excluded "married" couples who had different ZIP codes for their mailing addresses. (This would exclude those married couples where one member of the couples lives in a nursing home and has his/her mail delivered to that nursing home rather than to the family home.) The married couples identified through this algorithm have been shown to be quite similar to the national population of elderly married couples (Iwashyna et al., 2002). Moreover, and notably, identification of marital status is in no way predicated upon health care utilization experience. All comparisons here are between the married and the widowed.

For the purposes of the current study, we also required that the individual have been initially hospitalized at a hospital that could be linked to the American Hospital Association survey data in order to identify teaching hospitals and have a valid county identifier in the claims; $609,016(95.3 \%$ of 638,918$)$ were therefore analyzed.

Medicare data have certain well-known limitations with respect to their racial classification system, and the race codes provided in the claims can only be reliably used for white/non-white comparisons (Arday, Arday, Monroe, \& Zhang, 2000; Lauderdale \& Goldberg, 1996). Medicaid receipt, a measure of impoverishment, was obtained directly from the Denominator File, as is conventionally done (Carpenter, 1998; Clark \& Hulbert, 1998; Escarce, Epstein, Colby, \& Schwartz, 1993; Ettner, 1998; Khandker \& McCormack, 1999; Liu, Long, \& Aragon, 1998; Parente \& Evans, 1998; Pope, Adamache, Walsh, \& Khandker, 1998). We have linked at the ZIPcode level to 1990 Decennial Census median incomes. ZIP codes aggregate 25,000-50,000 people and this linkage provides a continuous measure that is likely well correlated with household-level total financial resources. This approach has been validated (Hofer, Wolfe, Tedeschi, MacMahon, \& Griffith, 1998; Krieger, 1992) for use as a control variable, but has certain well-described limitations (Geronimus \& Bound, 1998; Geronimus, Bound, \& Neidert, 1996; Robinson, 1950) which we have accommodated to the extent possible.

This research was approved by our Human Subjects Committee.

\section{Outcome variables}

We use multiple indicators of hospital attributes to increase the robustness of our interpretation. First, teaching hospitals are those that are members of the Council of Teaching Hospitals; this includes all hospitals that have residency programs. Such hospitals appear to improve short-term patient outcomes among the elderly (Taylor, Whellan, \& Sloan, 1999; Yaun, Cooper, Einstadter, Cebul, \& Rimm, 2000). Second, we also noted all hospitals which were presented as top performers in any of six specialties important to COSI patients in the 1993 US News and World Report rankings (Hill \& Rudolph, 1993; Hill, Winfrey, \& Rudolph, 1997). These hospitals have been shown to provide better care to heart attack patients (Chen et al., 1999). Third, every year, the American Hospital Association (AHA) surveys all of its members on the services that they provide; this information is generally considered the best census of hospitals that is available (American Hospital Association, 1994). From the AHA Survey data, we obtained information for a technology index. The technology index scores the presence of 27 items, with more rare items adding more points. Its performance and details of its construction are described elsewhere (Baker \& Spetz, 1999).

Our other outcome measures were as follows. Length of stay was obtained from the claims. Because of its highly skewed distribution, it is modeled as the logarithm of length of stay to the base of 2 . This means that a coefficient of 1.00 represents a doubling of the length of stay; the coefficients cannot be validly 
transformed to predict absolute numbers of days (Manning, 1998). As all hospital stays in our data were purchased on a per-visit basis by HCFA during qthe period under study, hospitals have strong incentives to discharge patients as rapidly as possible (costs increase with length of stay, but reimbursement does not).

If the widowed received lower quality care, their lengths of stay might be inappropriately shortened. To check for the possibility that the widowed were receiving poorer care in this measure, we examine whether the patients who survived their initial admission were readmitted to any hospital within 14 days. We examined for these early readmissions, which have been used extensively, particularly in the heart failure literature, as an indicator of inappropriately rapid discharge or substandard care (Chin \& Goldman, 1997; Krumholz et al., 1997; Wray, Peterson, Souchek, Ashton, \& Hollingsworth, 1997). If a patient is given good care, he or she should not need to return to the hospital within 2 weeks of discharge. It is generally argued that early readmission rates are primarily an indicator of the quality of care received at the hospital, rather than an indicator of the quality of the immediate post-hospitalization care. That is, they are argued to be, in general, not sensitive to the quality of home care. If the married receive better care than the widowed, we would expect the married to have lower rates of early readmission. Finally, as an alternative indicator of quality of care, we examined the impact of marital status on rates of complications as recorded in the claims, using either the DesHarnais system (DesHarnais, McMahon, Wroblewski, \& Hogan, 1990) or the so-called "E-codes" of explicitly listed complications. Similar results to those presented below were obtained, but these data are not shown.

\section{Analytic approach: hierarchical linear models}

The married and the widowed are not evenly distributed in space. In order to get accurate estimates of the effects of individual characteristics given the set of feasible hospital options that they have, we exploit hierarchical linear models (HLM) to allow a varying fixed effect for each level of aggregation.

As a concrete example, consider our first question: how do the married differ from the widowed in their likelihood of using a teaching hospital for their initial care? If the married and the widowed are not uniformly distributed across the country, then in order to answer this question, we need to understand how the availability of teaching hospitals differs and take that into account. Rather than develop ad hoc cut points or arbitrarily defined choice sets (e.g., all hospitals within 50 miles of the patient's house), we simply look at each county and ask: what characteristics of the individuals within this county determined whether or not they went to a teaching hospital. We repeat this for all counties, using HLM to take into account the clustering of the data. Thus, we assume that if any individuals in a county were able to attend a teaching hospital, there was some physical feasibility for all patients to do so - and we try to understand what characteristics affect an individual's ability to take advantage of that feasibility, relative to similarly situated others.

By allowing each county to vary in its average propensity to use a teaching hospital, we can look at the effects of individual characteristics net of all characteristics that are constant at the county-level, without needing to measure them (Bryk \& Raudenbush, 1992; Iwashyna, Curlin, \& Christakis, 2002). Thus, we assume that within counties, the married and the widowed are approximately homogeneously distributed with respect to distance to teaching hospitals and also with respect to other variables not causally related to marital status. That is, we make the plausible but untested assumption that those who live close to a teaching hospital are not less likely to become widowed, and therefore that if the married are more likely to go to a teaching hospital, causality runs directly from marital status to hospital use, not via some confounding variable. Within this analytic framework, we examine three types of variables: characteristics of the initial hospital used by the seriously ill given the county in which they reside; length of stay given the hospital used; and early readmission rates given the hospital used. Note that this does not require that the hospital used actually be within the county of interest - it merely looks within those counties in which there is variation on whether or not a teaching hospital was used, and asks: are the married more likely to go to a teaching hospital, all else equal?

Technically, we use two-level hierarchical modeling for individuals nested within counties (Bryk \& Raudenbush, 1992). Given the clustering of individuals within counties, hierarchical modeling is ideally required to generate unbiased and efficient estimates, as well as proper standard errors. Such modeling can take into account (a) the influence of different sample sizes across counties and (b) the dependence among individual outcomes clustered within the same county. A logistic model was used at level-1 for dichotomous outcomes. Individual-level variables were entered group-mean centered, and the variance components of their slopes were fixed at the county-level, in order to assess for variation between individuals (in odds of teaching hospital use) adjusted for differences between counties in all county-level factors. The level-2 variance component on the intercept was allowed to vary and was always significantly different from zero; its magnitude has no meaningful interpretation for categorical outcome regressions. 
A similar approach was taken for modeling length of stay and early readmission. In these cases, the level-2 units of analyses were the hospitals used. In this case, the unit-specific effects that are reported are interpretable as the average effect of differences in individual characteristics holding constant all hospital-characteristics; that is, they are within-hospital effects.

\section{Choice of counties to approximate available hospitals}

There are a number of difficult methodologic issues involved in defining health care markets. Some have strongly advocated the use of the Hospital Referral Regions (Wennberg \& Cooper, 1998) others the use of network-based measures (Phibbs \& Robinson, 1993; Sohn, 1996; Succi, Lee, \& Alexander, 1997) and others counties. In this project, we have used counties to approximate markets - that is, to approximate the community of people who share similar health care options - as has been done in numerous other studies (Banaszak-Holl, Zinn, \& Mor, 1996; Halfon, Newacheck, Wood, \& St Peter, 1996; Hartley, Moscovice, \& Christianson, 1996; Kerstein, Pauly, \& Hillman, 1994; Lafata, Koch, \& Weissert, 1994; Lambrew \& Ricketts, 1993; Mullan, Politzer, \& Davis, 1995; Murtaugh, 1994; Padgett, Patrick, Burns, \& Schlesinger, 1994; Roetzheim et al., 1999; Succi et al., 1997; Wholey, Christianson, Engberg, \& Bryce, 1997). This was done for a number of reasons: (1) our intuition that counties best approximate the way patients think about where they might go for care; (2) empirical tractability and availability of data; (3) the fact that counties are much smaller than HRRs, offering more nuanced controls for the availability of hospitals for our models; and (4) past work suggesting that results are often (but not always) insensitive to the difference between HRRs and counties - that these differences are particularly small for medical diagnoses of the type we study here (McLaughlin, Normolle, Wolfe, McMahon, \& Griffith, 1989).

\section{Results}

Basic descriptive statistics are shown in Table 1. There are 609,016 individuals overall, and $50.0 \%$ were widowed at the start of their index hospitalization. Their mean age was 79.3 and $44.0 \%$ were male. Consistent with the elderly population, $90.4 \%$ were white and $11.5 \%$ qualified for Medicaid in 1993 (US Bureau of the Census, 1996). A total of $24.1 \%$ sought hospital care for an illness that would be diagnosed as cancer, and the remaining cases were evenly divided among heart attack, congestive heart failure, hip fracture, and stroke. Their mean Charlson comorbidity score was a typical and modest value of 1.03 .

\section{Initial hospital choice}

Results for two categorical indicators of quality are shown in Table 2: whether a hospital was a teaching hospital and whether it was a US News \& World Report ranked hospital in 1993. They present a consistent picture. Those who are widowed at baseline have a $8 \%$ lower odds of going to a teaching hospital and a $17 \%$ lower odds of going to a ranked "Best" hospital. This effect does not vary by gender. The magnitudes are such that a married man on who was "poor" (i.e., who qualifies for Medicaid) and a widowed man who was not "poor" (i.e., who does not qualify for Medicaid) are about equally likely to go to a teaching hospital. These results were replicated within the subset of patients suffering from cancer to confirm that variation in the urgency of the primary diagnosis was not confounding the results; similar results were found (data not shown).

Hospitals with more advanced technology are often considered better hospitals. As shown in Table 3, older, poorer, sicker (more comorbidities), and female probands tend to go to hospitals with less technology. Pertinently, patients who are widowed at baseline go to hospitals with less technology; this effect is substantially more pronounced in men than in woman.

\section{Length of stay}

The results for length of stay are presented in Table 4 . For these analyses, we have changed the level-2 unit of

Table 1

Description of cohort

\begin{tabular}{lc}
\hline & Mean \\
\hline Age & 79.3 \\
Male & $44.0 \%$ \\
White & $90.4 \%$ \\
Medicaid & $11.5 \%$ \\
ZIP median income (\$1k) & 30.1 \\
Widowed & $50.0 \%$ \\
& \\
Primary diagnosis & \\
Cancer & $24.1 \%$ \\
Heart attack & $18.0 \%$ \\
Congestive heart failure & $20.1 \%$ \\
Hip fracture & $17.0 \%$ \\
Stroke & $20.0 \%$ \\
& \\
Charlson score (3 year mean) & 1.03 \\
& \\
Index hospital & \\
$\quad$ Was a teaching hospital & \\
$\quad$ Was a "Best" hospital & $11.7 \%$ \\
$\quad$ Technology index & $6.9 \%$ \\
Length of stay (mean days) & 7.24 \\
& 9.11 \\
\hline
\end{tabular}


Table 2

Impact of marital status on choice of teaching hospital or "Best" hospital

\begin{tabular}{|c|c|c|c|c|c|c|c|c|}
\hline & \multicolumn{4}{|c|}{ Teaching hospital } & \multicolumn{4}{|c|}{ "Best" hospital by M.D. Survey } \\
\hline & Odds ratio & Lower bound & Upper bound & $p$-value & Odds ratio & Lower bound & Upper bound & $p$-value \\
\hline Age & 0.98 & 0.98 & 0.98 & $<0.001$ & 0.98 & 0.98 & 0.98 & $<0.001$ \\
\hline Male & 1.03 & 1.00 & 1.06 & 0.051 & 1.03 & 1.00 & 1.07 & 0.069 \\
\hline White & 0.67 & 0.65 & 0.69 & $<0.001$ & 0.68 & 0.66 & 0.71 & $<0.001$ \\
\hline Medicaid & 0.89 & 0.86 & 0.92 & $<0.001$ & 0.78 & 0.75 & 0.82 & $<0.001$ \\
\hline ZIP median income $(\$ 1 \mathrm{k})$ & 1.00 & 1.00 & 1.00 & 0.495 & 1.01 & 1.01 & 1.01 & $<0.001$ \\
\hline Widowed & 0.92 & 0.89 & 0.94 & $<0.001$ & 0.86 & 0.83 & 0.89 & $<0.001$ \\
\hline Male*widow & 1.01 & 0.96 & 1.05 & 0.789 & 1.02 & 0.96 & 1.08 & 0.515 \\
\hline
\end{tabular}

Both regressions also controlled for primary diagnosis ( 12 dummies) and Charlson comorbidity index ( 24 dummies). $95 \%$ confidence intervals are presented for the odds ratio. HLM level-2 units were counties.

Table 3

Impact of marital status on technology index of chosen hospital

\begin{tabular}{lrlr}
\hline & Coefficient & Standard error & $p$-value \\
\hline Age & -0.03 & 0.00 & $<0.001$ \\
Male & 0.09 & 0.01 & $<0.001$ \\
White & -0.19 & 0.06 & 0.002 \\
Medicaid & -0.42 & 0.02 & $<0.001$ \\
ZIP median income $(\$ 1 \mathrm{k})$ & 0.01 & 0.00 & $<0.001$ \\
Widowed & -0.05 & 0.02 & 0.002 \\
Male*widow & -0.09 & 0.02 & $<0.001$ \\
\hline
\end{tabular}

The regression also controlled for primary diagnosis (12 dummies) and Charlson comorbidity index (24 dummies). HLM level-2 units were counties.

Table 4

Impact of marital status on length of stay

\begin{tabular}{|c|c|c|c|}
\hline & Coefficient & Standard error & $p$-value \\
\hline Age (10 years) & 0.047 & 0.003 & $<0.001$ \\
\hline Male & -0.040 & 0.004 & $<0.001$ \\
\hline White & -0.061 & 0.005 & $<0.001$ \\
\hline Medicaid & 0.074 & 0.004 & $<0.001$ \\
\hline ZIP median income $(\$ 10 \mathrm{k}$ & -0.011 & 0.001 & $<0.001$ \\
\hline Widowed & 0.015 & 0.004 & $<0.001$ \\
\hline Male*widow & 0.017 & 0.007 & 0.012 \\
\hline
\end{tabular}

Outcome variable was $\log _{2}$ of length of stay. The regression also controlled for primary diagnosis (12 dummies) and Charlson comorbidity index (24 dummies). HLM level-2 units were hospitals.

aggregation in the HLM models. We are no longer looking at the choices of people within counties; we now look at the experience of patients at the finer level of hospitals. Older, female, non-white, and poor individuals have longer lengths of stay within any given hospital. Women who are widowed at diagnosis have longer lengths of stay - equivalent to being three years older. Men who are widowed at diagnosis have substantially longer lengths of stay - their increase is two times greater than widowed women $(0.015+0.017=0.032$ vs. 0.015$)$. For men who have lost a spouse, they have the same increase in their length of stay that is associated with having a Charlson score of about 2-that is, equivalent to having moderate to severe diabetes vs. lacking that disease. (Patients with a Charlson score of 2 have a coefficient of 0.037 relative to those with a Charlson score of 0 .)

\section{Early readmission rates}

A total of 546,407 patients survived their initial admission and were therefore were at risk for early readmission. The overall rate of readmission within 14 days among these patients is $8.8 \%$. As shown in Table 5, men are more likely to be readmitted, as are individuals with more comorbidity. However, the estimated effects of marital status on readmission rates are trivial and statistically insignificant - the estimated magnitude is less than $10 \%$ of the effect of moving from a Charlson score of $0-1$. It was possible that the processes leading to longer stays for the widowed might be masking a tendency to have increased readmission at any given length of stay; however, when we conducted analyses that stratified on length of stay, we found similar null results. Likewise, analyses within those patients who had congestive heart failure failed to find a substantial marital status effect.

Similar results were found in a replication of these analyses looking at whether patients suffered from complications of care (data not shown). That is, there is no evidence that the married are receiving better care net of their hospital choice.

\section{Discussion}

These results show a clear pattern that the married receive different care and do so at different sites than do 
Table 5

Impact of marital status on rates of early readmission

\begin{tabular}{llllr}
\hline & Odds ratio & Lower bound & Upper bound & $p$-value \\
\hline Age (10 years) & 1.002 & 1.001 & 1.004 & 0.008 \\
Male & 1.155 & 1.121 & 1.191 & 0.001 \\
White & 0.958 & 0.924 & 0.992 & 0.016 \\
Medicaid & 1.083 & 1.049 & 1.117 & 0.001 \\
ZIP median income (\$10k) & 1.000 & 0.999 & 1.001 & 0.716 \\
Widowed & 1.007 & 0.976 & 1.038 & 0.677 \\
Male*widow & 0.964 & 0.920 & 1.009 & 0.114 \\
\hline
\end{tabular}

Outcome variable was readmission to any hospital within 14 days of discharge for patients who survived their initial hospitalization. The regression also controlled for primary diagnosis (12 dummies) and Charlson comorbidity index ( 24 dummies). $95 \%$ confidence intervals are presented. HLM level-2 units were hospitals.

the widowed, with the married using sites that are ostensibly better. This was true on three different indicators. After controlling for all attributes of the local health care market using a fixed effect model, the married were more likely to go to teaching hospitals, "best" hospitals, and higher tech hospitals. On the other hand, the quality of care at any given site seems similar; the length of stay of the widowed appears to be greater than the married (suggesting that the widowed are not being prematurely discharged from care-indeed, not having a spouse at home may impede discharge), and the widowed did not have higher early readmission rates.

The data presented here show that marital status is associated with differences in the type of care received. It is logically possible that the direction of causality runs from type of care chosen to marital status rather than the other way. Thus, perhaps those who choose lower quality medical care are less able to get care for their spouses, and therefore are more likely to become widowed. While plausible, and while the data here cannot exclude this interpretation, we do not believe that this is the cause of our results. There have been a number of rigorous studies demonstrating that the changes in marital status are tightly coupled to changes in behavior within individuals. This is true of hours worked, engagement in crime, and a host of forms of community engagement (Daniel, 1993; Laub, Nagin, \& Sampson, 1998; Nock, 1998). It therefore seems likely that changes in marital status would also lead to differences in health care utilization. This same pattern (within longitudinal data and with a different set of controls for health) has been shown in the case of total hospital use and of mental health use (Prigerson et al., 1999). In this analysis, we have used a novel data set and a methodology that solves the problem of how to correctly take into account variation in the opportunities individuals faced. Nevertheless, future work will be needed to definitely rule out selection bias.

This work has a number of other limitations. First of all, we have only compared two marital statuses - the married and the widowed. Although currently rare among the elderly, divorce and cohabitation are becoming more common and might have different effects on our outcomes (Bumpass \& Sweet, 1989; Chevan, 1996; US Bureau of the Census, 1996). (Among men, $76.5 \%$ of the current elderly are married, $14.2 \%$ are widowed, and only $9.2 \%$ are divorced or single as of 1990; for women those numbers are $41.5 \%, 48.6 \%$, and $10.0 \%$, respectively.) Second, we have only looked at the elderly. While this provides access to adequate data and is the point in the life course where most serious healthcare use occurs, an examination in a broader age range would complement these results. Third, we have looked only at the choice of initial hospitalization for serious illness. While we believe this provides an excellent view from which to understand the way marital status is related to household decisions about care use, other effects might be possible in the search for care by the less ill or among patients after diagnosis (although our review of the literature leads us to expect similar findings to the present ones). Fourth, we have only looked at hospital care. While there is evidence reviewed above that similar patterns may obtain in other setting, this needs to be directly confirmed. Finally, we have used the claims data to develop our covariates. While this allows for excellent information about health-care use without recourse to proxies and without the limitations of non-response, the use of claims limits our ability to control for potential confounders such as the availability of children or the "quality" of the marriage in any sense (Ross, 1995). More generally, in this initial exploration, we have not examined the ways in which other institutional structures (such as community size (Seeman et al., 1993), racial integration (Iwashyna, Christakis, \& Becker, 1999), church participation, or governmental programs) may compensate for or exacerbate the differences between the married and the widowed; understanding such mechanisms which modify the effects of marriage is a natural step for future work. 


\section{An interpretation}

There are at least four possible and speculative explanations for our results. One possibility is that the married may be steered towards better health care by their providers. However, that the married and widowed receive similar care inside a given hospital suggests - but does not prove-that other providers outside the hospital might also not discriminate on the basis of marital status, thus making this possibility less likely. Second, the married and the widowed might have differential access to health insurance, particularly during middle age. While this may be true, the current results have looked only within the widely accepted fee-for-service Medicare system; that is, there are no insurance-related barriers to health care. Third, the married and the widowed may have differences in wealth, and the consequent ability to purchase care. While we cannot rule this out, we have controlled for such differences using a variety of techniques, and, again, all these (elderly) patients were on Medicare.

Finally, the married may have access to better information and better referral networks: better informed, they are able to make better choices about which hospitals to use and how to use them. Our results provide suggestive evidence that this going on: the married appear to be different on variables where they have a choice (hospital quality) but not when the patients have little input (rates of substandard care). This suggests that the married may have better access to information about "better" care - and that the choice to pursue better care may be made within the household, rather than foisted upon it by external structures. Since, in our data, this occurs before the particular diagnosis is known - that is, when a patient is quite ill, but may not yet know why-it suggests that marriage may provide the interpersonal resources necessary to develop and execute a better algorithm for care seeking.

This has implications for the way we think about the relationship between marriage and health. There has been a substantial line of work that emphasizes the role of spouses - and, in particular, of wives - in exerting normative control over the day-to-day actions of their spouse (Umberson, 1987; Umberson, 1992). A parallel argument emphasizes the availability of spouses as an "informal group" that can provide day-to-day help (Litwak et al., 1989). Other research has suggested the marriage is of crucial importance in understanding whether or not debilitated elderly use nursing homes (Freedman 1996; Freedman et al., 1994). And certainly marriage is important at this micro-level. However, interventions implied by this research tradition (e.g., the provision of home health aides) have been largely ineffectual at changing measurable outcomes (Freedman \& Reschovsky, 1997; Hadley, Rabin, Epstein, Stein, \&
Rimes, 2000; Welch, Wennberg, \& Welch, 1996). This suggests that the health benefits of marriage may come through means other than day-to-day practical help.

Our results suggest another possibility. Whatever else marriage does, it may also provide higher order resources. That is, marriage may act by not merely facilitating the day-to-day achievement of particular goals. Marriage may also provide the resources to change the broad approach to choosing goals. These resources could take many forms: the time to research differences in hospitals; broader social networks that offer easier access to information and resources; greater help getting to the most desired or most optimal kinds of care. All of these likely contribute. These broad sorts of differences are precisely what one prior review of the effects of marriage suggests: that, for example, the impact of marriage on men's lives is not so much to change whether, at the margin, someone goes to a bar or not. Instead, marriage changes the sort of lifestyle a man wants to lead, and the choice of going to a bar or not follows naturally (Nock, 1998). Similarly, in this case, it appears that marriage may change the orientation of individuals to the sort of care they seek when becoming ill: they may go after higher quality care more vigorously. Moreover, our findings suggest that they may have developed this algorithm for care-seeking before they know their diagnosis - that is, this "better" algorithm may be a part of their approach to life.

\section{Conclusion}

As the fraction of the elderly population that is married declines, the impact of marital status on health care choices could be quite important. To date, most intervention efforts have focused on remedying the home care needs of the widowed. Our work suggests an alternative focus at which help can be directed. If the married are better able to plan their care than are the widowed, it may be more fruitful to direct resources towards long-term care management and planning. Spouses, after all, are far more than just help at home: they are partners in the planning of one's life and the confrontation of adversity.

\section{Acknowledgements}

This work was supported in part by a grant from NIA (R-01 AG15326-01) (NAC) and the Robert Wood Johnson Investigator Awards (NAC), and in part by a National Research Service Award from the NIH/ National Institute on Aging (T32-AG00243) (TJI). We thank James X. Zhang for his excellent programming, and Linda $\mathrm{J}$. Waite and Robert T. Michael for their comments on an earlier draft of this manuscript. 


\section{References}

American Hospital Association (1994). The annual survey of hospitals database documentation for 1993 data. Chicago: American Hospital Association.

Arday, S. L., Arday, D. R., Monroe, S., \& Zhang, J. (2000). HCFA's racial and ethnic data: Current accuracy and recent improvements. Health Care Financing Review, 21, 107-116.

Baker, L., \& Spetz, J. (1999). Managed care and medical technology growth. NBER Working Paper Series, 6894.

Banaszak-Holl, J., Zinn, J. S., \& Mor, V. (1996). The impact of market and organizational characteristics on nursing care facility service innovation: A resource dependency perspective. Health Services Research, 31, 97-117.

Benesch, C., Witter Jr., D. M., Wilder, A. L., Duncan, P. W., Samsa, G. P., \& Matchar, D. B. (1997). Inaccuracy of the international classification of disease (ICD-9-CM) in identifying the diagnosis of ischemic cerebrovascular disease. Neurology, 49, 660-664.

Bernabei, R., Gambassi, G., Lapane, K., Landi, F., Gatsonis, C., Dunlop, R., Lipsitz, L., Steel, K., Mor, V., \& SAGE Study Group (1998). Management of pain in elderly patients with cancer. Journal of the American Medical Association, 279, 1877-1882.

Bryk, A. S., \& Raudenbush, S. W. (1992). Hierarchical linear models. Newbury Park, CA: Sage.

Bumpass, L. L., \& Sweet, J. A. (1989). National estimates of cohabitation. Demography, 26, 615-626.

Carpenter, L. (1998). Evolution of medicaid coverage of medicare cost sharing. Health Care Financing Review, 20, 11-18.

Charlson, M. E., Pompei, P., Ales, K. L., \& MacKenzie, C. R. (1987). A new method of classifying prognostic comorbidity in longitudinal studies: Development and validation. Journal of Chronic Disease, 40, 373-383.

Chen, J., Radford, M. J., Yun, W., Marciniak, T. A., \& Krumholz, H. M. (1999). Do "America's Best Hospitals" perform better for acute myocardial infarction? New England Journal of Medicine, 340, 286-292.

Chevan, A. (1996). As cheaply as one: Cohabitation in the older population. Journal of Marriage and The Family, 58, 656-667.

Chin, M. H., \& Goldman, L. (1997). Correlates of early hospital readmission or death in patients with congestive heart failure. The American Journal of Cardiology, 79, 1640-1644.

Christakis, N. A., Iwashyna, T. J., \& Zhang, J. X. (2002). Care after the onset of serious illness (COSI): A novel claimsbased data set exploiting substantial cross-set linkages to study end-of-life care. Journal of Palliative Medicine, 5(4), 515-530.

Clark, W. D., \& Hulbert, M. M. (1998). Research issues: Dually eligible medicare and medicaid beneficiaries, challenges and opportunities. Health Care Financing Review, 20, 1-10.

Daniel, K. E. (1993). Does marriage make workers more productive? Chicago: Department of Economics, University of Chicago.

DesHarnais, S. I., McMahon Jr., L. F., Wroblewski, R. T., \& Hogan, A. J. (1990). Measuring hospital performance: The development and validation of risk-adjusted indexes of mortality, readmissions, and complications. Medical Care, $28,1127-1141$.
Deyo, R. A., Cherkin, D. C., \& Ciol, M. A. (1992). Adapting a clinical comorbidity index for use with ICD-9-CM administrative databases. Journal of Clinical Epidemiology, 45, 613-619.

Escarce, J. J, Epstein, K. R., Colby, D. C., \& Schwartz, J. S. (1993). Racial differences in the elderly's use of medical procedures and diagnostic tests. American Journal of Public Health, 83, 948-954.

Ettner, S. L. (1998). Inpatient psychiatric care of medicare beneficiaries with state buy-in coverage. Health Care Financing Review, 20, 55-69.

Freedman, V. A. (1996). Family structure and the risk of nursing home admission. Journal of Gerontology: Social Sciences, 51B, S61-S69.

Freedman, V. A., Berkman, L. F., Rapp, S. R., \& Ostfeld, A. (1994). Family networks: Predictors of nursing home entry. American Journal of Public Health, 84, 843-845.

Freedman, V. A., \& Reschovsky, J. D. (1997). Differences across payors in charges for agency-based home health services: Evidence from the national home and hospice care survey. HSR: Health Services Research, 32, 433-452.

Geronimus, A. T., \& Bound, J. (1998). Use of census-based aggregate variables to proxy for socioeconomic group: Evidence from national samples. American Journal of Epidemiology, 148, 475-486.

Geronimus, A. T., Bound, J., \& Neidert, L. J. (1996). On the validity of using census geocode characteristics to proxy individual socioeconomic characteristics. Journal of the American Statistical Association, 91, 529-537.

Goodwin, J. S., Hunt, W. C., Key, C. R., \& Samet, J. M. (1987). The effect of marital status on stage, treatment, and survival of cancer patients. Journal of the American Medical Association, 258, 3125-3130.

Hadley, J., Rabin, D., Epstein, A., Stein, S., \& Rimes, C. (2000). Posthospitalization home health-care use and changes in functional status in a medicare population. Medical Care, 38, 494-507.

Halfon, N., Newacheck, P. W., Wood, D. L., \& St Peter, R. F. (1996). Routine emergency department use for sick care by children in the United States. Pediatrics, 98, 28-34.

Hartley, D., Moscovice, I., \& Christianson, J. (1996). Mobile technology in rural hospitals: The case of the CT scanner. Health Services Research, 31, 213-234.

Hatten, J. (1980). Medicare's common denominator: The covered population. Health Care Financing Review: Fall 53-64.

Health Care Financing Administration (1998). Medicare chart book. Bethesda, MD: HCFA Bureau of Data Management and Strategy.

Hill, C. A., \& Rudolph, B. A. (1993). The index of hospital quality: 1993 survey on best hospitals. Chicago: NORC.

Hill, C. A., Winfrey, K. L., \& Rudolph, B. A. (1997). "Best Hospitals": A description of the methodology for the index of hospital quality. Inquiry, 34, 80-90.

Hofer, T. P., Wolfe, R. A., Tedeschi, P. J., MacMahon, L. F., \& Griffith, J. R. (1998). Use of community versus individual socioeconomic data in predicting variation in hospital use. HSR: Health Services Research, 33, 243-259.

Iwashyna, T. J., Brennan, G., Zhang, J. X., \& Christakis, N. A. (2002). Finding married couples in the medicare claims data. 
Health Services and Outcomes Research Methodology, 3(1), 75-86.

Iwashyna, T. J., Christakis, N. A., \& Becker, L. B. (1999). Neighborhoods matter: A population-based student of CPR provision. Annals of Emergency Medicine, 34, 459-468.

Iwashyna, T. J., Curlin, F. A., \& Christakis, N. A. (2002). Racial, ethnic, and affluence differences in elderly patients' use of teaching hospitals. Journal of General Internal Medicine, 17, 696-703.

Iwashyna, T. J., Zhang, J. X., Lauderdale, D. S., \& Christakis, N. A. (1998). A methodology for identifying married couples in the medicare claims data: Mortality, morbidity and health care utilization among the elderly. Demography, 35, 413-419.

Iwashyna, T. J., Zhang, J. X., Lauderdale, D. S., \& Christakis, N. A. (2000). Refinements of a methodology for detecting married couples in the medicare claims. Demography, 37, 250-251.

Kerstein, J., Pauly, M. V., \& Hillman, A. (1994). Primary care physician turnover in HMOs. Health Services Research, 29, 17-37.

Khandker, R. K., \& McCormack, L. A. (1999). Medicare spending by beneficiaries with various type of supplemental insurance. Medical Care Research and Review, 56, 137-155.

Kohn, L. T., Corrigan, J. M., \& Donaldson, M. S. (2000). To err is human: Building a safer health system. Washington, DC: National Academy Press.

Korenman, S., Goldman, N., \& Fu, H. (1997). Misclassification bias in estimates of bereavement effects. American Journal of Epidemiology, 145, 995-1002.

Krieger, N. (1992). Overcoming the absence of socioeconomic data in medical records: Validation and application of a census-based methodology. American Journal of Public Health, 82, 703-710.

Krumholz, H. M., Parent, E. M., Tu, N., Vaccarino, V., Yun, W., Radford, M. J., \& Hennen, J. (1997). Readmission after hospitalization for congestive heart failure among medicare beneficiaries. Archives of Internal Medicine, 157, 99-104.

Krumholz, H. M., Radford, M. J., Yun, W., Chen, J., Heiat, A., \& Marciniak, T. A. (1998). National use and effectiveness of the beta-blockers for treatment of elderly patients after acute myocardial infarction. Journal of the American Medical Association, 280, 623-629.

Kuykendall, D. H., Ashton, C. M., Johnson, M. L., \& Geraci, J. M. (1995). Identifying complications and low provider adherence to normative practice using administrative data. HSR: Health Services Research, 30, 531-554.

Lafata, J. E., Koch, G. G., \& Weissert, W. G. (1994). Estimating activity limitation in the noninstitutionalized population: A method for small areas. American Journal of Public Health, 84, 1813-1817.

Lambrew, J. M., \& Ricketts, T. C. (1993). Patterns of obstetrical care in single-hospital, rural counties. Medical Care, 31, 822-833.

Lannin, D. R., Mathews, H. F., Mitchell, J., Swanson, M. S., Swanson, F. H., \& Edwards, M. S. (1998). Influence of socioeconomic and cultural factors on racial differences in late-stage presentation of breast cancer. Journal of the American Medical Association, 279, 1801-1807.

Laub, J. H., Nagin, D. S., \& Sampson, R. J. (1998). Trajectories of change in criminal offending: Good marriages and the desistance process. American Sociological Review, 63, 225-238.

Lauderdale, D. S., Furner, S. E., Miles, T. P., \& Golderberg, J. (1993). Epidemiologic uses of medicare data. Epidemiologic Reviews, 15, 319-327.

Lauderdale, D. S., \& Goldberg, J. (1996). The expanded racial and ethnic codes in the medicare data files: Their completeness of coverage and accuracy. American Journal of Public Health, 86, 712-716.

Levit, K., Cown, C., Lazenby, H., Sensenig, A., McDonnell, P., Stiller, J., \& Martin, A. (2000). Health spending in 1998: Signals of change. Health Affairs, 19, 124-132.

Lillard, L. A., \& Waite, L. J. (1995). Till death do us part: Marital disruption and mortality. American Journal of Sociology, 100, 1131-1156.

Litwak, E., Messeri, P., Wolfe, S., Gorman, S., Silverstein, M., \& Guilarte, M. (1989). Organizational theory, social supports, and mortality rates: A theoretical convergence. American Sociological Review, 54, 49-66.

Liu, K., Long, S. K., \& Aragon, C. (1998). Does health status explain higher medicare costs of medicaid enrollees? Health Care Financing Review, 20, 39-54.

Manning, W. G. (1998). The logged dependent variable, heteroscedasticity, and the retransformation problem. Journal of Health Economics, 17, 283-295.

Mark, T. L., \& Paramore, L. C. (1996). Pneumococcal pneumonia and influenza vaccination: Access to and use by hispanic medicare beneficiaries. American Journal of Public Health, 86, 1545-1550.

McBean, A. M., Babish, J. D., \& Warren, J. L. (1993). Determination of lung cancer incidence in the elderly using medicare claims data. American Journal of Epidemiology, 137, 226-234.

McBean, A. M., Warren, J. L., \& Babish, J. D. (1994). Measuring the incidence of cancer in elderly Americans using medicare claims data. Cancer, 73, 2417-2425.

McLaughlin, C. G., Normolle, D. P., Wolfe, R. A., McMahon Jr., L. F., \& Griffith, J. R. (1989). Small-area variation in hospital discharge rates: Do socioeconomic variables matter? Medical Care, 27, 507-521.

Mineau, G. P., Smith, K. R., \& Bean, L. L. (2002). Historical trends of survival among widows and widowers. Social Science and Medicine, 54, 245-254.

Mullan, F., Politzer, R. M., \& Davis, C. H. (1995). Medical migration and the physician workforce. International medical graduates and American medicine. Journal of the American Medical Association, 273, 1521-1527.

Murtaugh, C. M. (1994). Discharge planning in nursing homes. Health Services Research, 28, 751-769.

Nock, S. L. (1998). Marriage in men's lives. New York: Oxford University Press.

Padgett, D. K., Patrick, C., Burns, B. J., \& Schlesinger, H. J. (1994). Ethnic differences in use of inpatient mental health services by blacks, whites, and Hispanics in a national insured population. Health Services Research, 29, 135-153.

Parente, S. T., \& Evans, W. N. (1998). Effect of low-income elderly insurance copayment subsidies. Health Care Financing Review, 20, 19-38.

Phibbs, C. S., \& Robinson, J. C. (1993). A variable-radius measure of local hospital market structure. Health Services Research, 28, 313-324. 
Pope, G. C., Adamache, K. W., Walsh, E. G., \& Khandker, R. K. (1998). Evaluating alternative risk adjusters for medicare. Health Care Financing Review, 20, 109-129.

Prigerson, H. G., Maciejewski, P. K., \& Rosenheck, R. A. (1999). The effects of marital dissolution and marital quality on health and health service use among women. Medical Care, 37, 858-873.

Robinson, W. S. (1950). Ecological correlations and the behavior of individuals. American Sociological Review, 15, 351-357.

Roetzheim, R. G., Pal, N., Gonzalez, E. C., Ferrante, J. M., Van Durme, D. J., Ayanian, J. Z., \& Krischer, J. P. (1999). The effects of physician supply on the early detection of colorectal cancer. Journal of Family Practice, 48, 850-858.

Ross, C. (1995). Reconceptualizing marital status as a continuum of social attachment. Journal of Marriage and The Family, 57, 129-140.

Ross, C. E., Mirowsky, J., \& Goldsteen, K. (1990). The impact of family on health: A decade in review. Journal of Marriage and The Family, 52, 1059-1078.

Seeman, T. E., Berkman, L. F., Kohout, F., Lacroix, A., Glynn, R., \& Blazer, D. (1993). Intercommunity variations in the association between social ties and mortality in the elderly: A comparative analysis of three communities. Annals of Epidemiology, 3, 325-335.

Smith, K. R., \& Waitzman, N. J. (1994). Double jeopardy: Interaction effects of marital and poverty status on the risk of mortality. Demography, 31, 487-507.

Smith, K. R., \& Zick, C. D. (1994). Linked lives, dependent demise? Survival analysis of husbands and wives. Demography, 31, 81-89.

Sohn, M-. W. (1996). From regional to local markets: Network study of competition in California hospital markets. Chicago: University of Chicago.

Sox, C. M., Schwartz, K., Burstin, H. R., \& Brennan, T. A. (1998). Insurance or a regular physician: Which is the most powerful predictor of health care. American Journal of Public Health, 88, 364-370.
Succi, M. J., Lee, S. Y., \& Alexander, J. A. (1997). Effects of market position and competition on rural hospital closures. Health Services Research, 31, 679-699.

Taylor, D. H., Whellan, D. J., \& Sloan, F. A. (1999). Effects of admission to a teaching hospital on the cost and quality of care for medicare beneficiaries. New England Journal of Medicine, 340, 293-299.

US Bureau of the Census (1996). Current population reports, special studies, P23-190, 65+ in the United States. Washington, DC: US Government Printing Office.

Umberson, D. (1987). Family status and health behaviors: Social control as a dimension of social integration. Journal of Health and Social Behavior, 28, 306-319.

Umberson, D. (1992). Gender, marital status and the social control of health behavior. Social Science and Medicine, 34, 907-917.

Welch, H. G, Wennberg, D. E., \& Welch, W. P. (1996). The use of medicare home health care services. New England Journal of Medicine, 335, 324-329.

Wennberg, J. E., Cooper, M. M. (1998). The dartmouth atlas of health care: American Hospital Publishing. Chicago, IL.

Wholey, D. R., Christianson, J. B., Engberg, J., \& Bryce, C. (1997). HMO market structure and performance: 19851995. Health Affairs, 16, 75-84.

Wray, N. P., Peterson, N. J., Souchek, J., Ashton, C. M., \& Hollingsworth, J. C. (1997). Application of an analytic model to early readmission rates within the department of veterans affairs. Medical Care, 35, 768-781.

Yaun, Z., Cooper, G. S., Einstadter, D., Cebul, R. D., \& Rimm, A. A. (2000). The association between hospital type and mortality and length of stay: A study of 16.9 million hospitalized medicare beneficiaries. Medical Care, 38, 231-9245.

Zhang, J. X., Iwashyna, T. J., \& Christakis, N. A. (1999). The impact of alternative lookback periods and sources of information on Charlson comorbidity adjustment in medicare claims. Medical Care, 37, 1128-1139. 